\title{
Students' Perceptions of Emergency Remote Instruction During the COVID-19 Pandemic
}

\author{
Sheryl-Ann K. Stephen \\ Butler University
}

\author{
Marleen McCormick-Pritchard \\ Butler University
}

In Spring 2020, the pandemic forced administrators and professors to pivot to emergency remote instruction in order to salvage the semester. This study examines students' perceptions of emergency remote instruction at a private university in the Midwestern US during the COVID-19 pandemic. The findings show that 55\% of students had never taken an online course prior to this experience. Moreover, $71 \%$ of students said that only a few professors were comfortable with the new online format and/or the use of technology, $78 \%$ of students perceived online instruction to be inferior to traditional classroom teaching, 87\% of students missed the face-to-face contact with their professors, and $90 \%$ of students missed the face-to-face contact with their peers. Students who identified as extroverts missed the face-to-face interaction with their peers more than the students who identified as introverts. Finally, about $28 \%$ of students reported belowaverage personal well-being after the pivot to emergency remote instruction.

Keywords: online instruction, students' perspectives, COVID-19, pandemic

\section{INTRODUCTION}

In January 2020, COVID-19, or the coronavirus as it was commonly called, spread from China, and created a dire global health crisis. By March 2020, in the middle of the Spring semester, educators all over the world suddenly found themselves teaching remotely because of the pandemic. Online learning offers more flexibility for students and universities; however, the emergency pivot to remote instruction did not give instructors much time to adapt the delivery of their courses to what they perceived as a novel environment. Thankfully, one upside was that many universities already had some infrastructure (e.g., learning management systems) in place to facilitate the move to remote instruction. As a result, students were able to continue their classes and progress toward their degree even as the world shut down around them.

It should be noted that remote or online learning involves more than just making content available online and delivering that content to students. Michelle D. Miller, a professor in the Department of Psychological Sciences at Northern Arizona University, stated the following: "The power of online learning doesn't come from the content itself, but rather from the active engagement students have with that content, with the faculty, and with one another. Accomplishing this kind of engagement requires not just technical skill on the part of the instructor, but also thoughtful design of the activities and interactions that are going 
to take place. Faculty teaching online need to be creative and need to have a deep understanding of how learning works as well as subject matter expertise, in order to make a course truly come alive for learners."

The sudden pivot to remote instruction during the pandemic did not afford many instructors the time necessary to become adept at engaging students in the online environment. Many instructors had not had any training in teaching online and therefore found it quite challenging. Likewise, many students had had little exposure to online education, and some had actually never taken an online course before. Therefore, many students were not prepared for the self-discipline required to succeed in the remote environment.

In addition to having to deal with the general uncertainty surrounding the COVID-19 pandemic, including the social and political upheaval, students had to deal with suddenly being thrust back into their homes, where they were forced to transition from traditional to online learning. As a result, many students were concerned about a possible decline in their academic performance due to resources, engagement, communication, and overall individual attention that were suddenly limited because of the pandemic. Also, many instructors were forced to handle various other duties, such as childcare, on top of preparing to take their courses online within an extremely short time frame.

Phipps and Merisotis (2000) identified 24 benchmarks that are key to ensuring excellence and high quality in online learning. These benchmarks address course development, course structure, evaluation and assessment, faculty support, student support, teaching and learning, technological issues, and institutional support. Additionally, Levy (2003) found that although there are many parallels in the development of online and traditional courses, instructors need training and support to be successful in the online teaching environment. In other words, instructors need support and training in pedagogy to understand how the details of their course can be adapted for the online or remote environment. Unfortunately, because the pandemic caught educational institutions off guard, many instructors did not have the luxury of training before being forced into the remote teaching environment.

It is against this backdrop that the authors investigate students' perceptions of emergency remote instruction during the COVID-19 pandemic. This study is warranted as it adds to the literature on remote learning and instruction, including student satisfaction with online education during an enforced change in instructional circumstances, in this case a global pandemic. It also provides valuable feedback on the quality of emergency remote learning and instruction from students' perspective specifically during the COVID19 pandemic. Finally, the study has significant implications for university policy as it pertains to online education.

Our results show that about $78 \%$ of students in our sample think that online instruction is inferior to traditional teaching methods, while only $5 \%$ think that online instruction is superior to traditional teaching methods. Of the students in our study, $87 \%$ said they missed the face-to-face contact with their professor, while $91 \%$ said they missed the face-to-face contact with their peers. Moreover, $36 \%$ of students "disliked" their Spring 2020 courses in the remote format, while 14\% "hated" their Spring 2020 courses in the remote format. About $18 \%$ of students neither liked nor disliked it, while $26 \%$ said they somewhat liked their Spring 2020 courses in the remote format. When asked how many of their professors were comfortable teaching in the emergency remote format, $42 \%$ of students said "a few," while $16 \%$ said "not many." Only $30 \%$ of students said most of their professors were comfortable teaching in the emergency remote format during the sudden pivot to remote instruction as a result of the COVID-19 pandemic.

The remainder of the paper is organized as follows. A literature review is followed by a description of the data and discussion of the research methodology. We then report the results, and a final section offers conclusions.

\section{LITERATURE REVIEW}

In examining students' perceptions of emergency remote instruction at the start of the COVID-19 pandemic, it is important to take a look at online education in general and the debate over its overall quality. Singh and Thurman (2019) defined online education as follows: education being delivered in an online environment through the use of the Internet for teaching and learning. This includes online learning on the part of the students that is not dependent on their physical or virtual colocation. The teaching content is 
delivered online, and the instructors develop teaching modules that enhance learning and interactivity in the synchronous or asynchronous environment.

The debate over the quality of online education has continued over the past two decades, or more. Proponents of online education say that the advancement of technology has facilitated the use of many options to substitute for face-to-face interaction. Mitchell et al. (2015) pointed out that the strongest argument for the adoption of online education is the need to keep up with technological advancements in our society. Video conferencing software such as Zoom, Microsoft Teams, Google Meet, and other products have been widely used to facilitate online education. Abrami et al. (2011) concluded that online instruction can deliver content in an innovative, efficient, and cost-effective manner. In addition, Ascough (2002) posited that online education can encourage students' critical-thinking skills, higher-order learning, team learning, and problem- solving skills. Likewise, Britt (2006) suggested that online instruction can potentially augment student independence, student retention, and higher-order thinking. It is also worth highlighting that the increase in research and pedagogical papers in the area of online education has equipped instructors with many tools and facilitated learning in the online environment (Parlamis \& Mitchell, 2014).

Opponents of online education generally perceive it to be inferior and used as simply a profit-generating machine for many universities. Li and Akins (2005) pointed out that opponents perceive online education as being limited to content learning, contributing to student isolation, encouraging student cheating, requiring both students and instructors to be proficient in technology, and being a one-way learning system. Wickersham and McElhany (2010) found that instructors generally agree that online courses compromise the quality of academic standards. More recent studies have found that online education widens the social divide and lacks the socialization aspect of education (Cole et al., 2014; Palvia et al., 2018; Richardson et al., 2017). Protopsaltis and Baum (2019) examined whether online education has been successful. The authors found that online education has not been completely successful, and that online courses have exacerbated widening gaps in educational success across socioeconomic groups, while at the same time they have not improved affordability.

Online education can undoubtedly present new opportunities and challenges for instructors. However, with the emergency pivot to remote teaching, both faculty and students have found it especially difficult because there was simply not enough time to prepare for the online environment. Moreover, faculty and students both have had to deal with the additional stressors (e.g., fear, sadness, worry, anxiety) inherent in a global pandemic.

\section{Instructor Preparation and Support}

The COVID-19 pandemic underscored the need for faculty to be ready and trained for online instruction. However, Cutri and Mena (2020) examined 44 studies to investigate faculty readiness for online teaching. The authors concluded that full professors place less emphasis on online course design and technical competency for remote teaching compared to junior faculty. Moreover, more senior faculty members are more inclined to resist teaching online. In a normal environment, institutional administrators need to have a deep understanding of these dynamics in order to better facilitate the transition to online instruction. Unfortunately, during the emergency pivot to remote teaching, there was hardly any time for administrators to address these different dynamics, which contributed to feelings of helplessness among faculty and students.

Shearer et al. (2020) used faculty and student focus groups to examine online education and specifically what students want. They found that faculty need to closely monitor students' progress and processes in order to provide timely support when needed. In addition, faculty need to be aware of the skills that students lack and provide them with the necessary cognitive, emotional, and social support to help them develop and be successful. Against the backdrop of a global pandemic, many faculty did not have the time needed to provide timely support to the students who needed it.

Fein and Logan (2003), in examining what is required to prepare instructors for online teaching, noted that a framework must be established and instructors must be supported by the institution before the course design phase. The authors emphasized that online instruction requires a heavier management workload 
(design, delivery, and follow- up) and instructors need a significant amount of support to succeed. Instructors must have the necessary support to adapt the classroom course to the remote environment. Also, according to the authors, instructors must be willing to make changes to the online course based on student feedback and personal experience. Teaching online is different from teaching in a classroom; therefore, instructors must be equipped with the skills, knowledge, and support they need to do so. According to Fein and Logan (2003), professional development courses and workshops in the area of online education should be mandatory for all instructors planning to teach online. Unfortunately, during the Spring semester of 2020, educational institutions were facing an emergency pivot to remote instruction, so there was very little time to make quality changes to courses for the remote environment.

\section{Challenges}

It is well known that online instruction is characterized by many challenges. Hinson and LaPrairie (2005) pointed out that the transition to online instruction can be quite arduous, as instructors tend to cling to instructional methods with which they are more familiar. One of the main challenges that instructors face is in the use of technology. This can be a steep learning curve for many instructors. Fein and Logan (2003) emphasized that the technology can and will cause problems, but instructors must become comfortable with the various options in order to provide a successful remote learning environment. The challenge with technology was magnified during the emergency pivot to remote instruction. Many instructors had just days to try to learn the technology, and that was a major obstacle for them to overcome.

Another challenge instructors face involves interacting with students in the online environment. Muirhead (2000) found that instructors are often confused on how to initiate interactions and build relationships with students online. Bower (2001) attributed this to the fact that instructors are trained in face-to-face teaching; therefore, they find it difficult to have interpersonal contact with students online. This issue was highlighted during the sudden pivot to emergency remote instruction. Even though instructors already had a relationship with their students, forged earlier in the Spring 2020 semester, they found it difficult to maintain these relationships, as both students and instructors were forced to deal with the emotional and mental toll of the pandemic.

\section{Student Satisfaction}

Shearer et al. (2020) surmised that students learn best through participating in in- depth discussions and interactions with their colleagues and instructors while attempting to solve real-world problems with critical and deep thinking. Moreover, students in the aforementioned study pointed out that the learning process needs to be collaborative and constructive and that they need to be an integral part of the inquiry. Once again, this was very difficult to achieve during the emergency pivot to remote instruction, and students missed the deep interactions with their peers and instructors.

Joosten and Cusatis (2020) investigated the link between student characteristics of online learning readiness and student outcomes in online courses at two higher educational institutions. The authors found that there are three main determinants of students' learning, satisfaction, and academic performance. Specifically, online learning efficacy, online work skills, and socialization were all significant in predicting students' satisfaction and learning. Wei and Chou (2020) developed a structural model to examine whether online learning perceptions and online learning readiness have an effect on students' online learning performance and course satisfaction. The authors found that online learning perceptions have a significant positive effect on online learning readiness.

Cole et al. (2014) investigated online instruction, e-learning, and student satisfaction over a 3-year time period. Their results showed that students were moderately satisfied with their online instruction; however, they rated hybrid courses as somewhat more satisfactory than fully online courses. In addition, "convenience" was the most cited reason for satisfaction, while "lack of interaction" was the most cited reason for dissatisfaction. Sher (2009) found that interaction among students and interaction between students and instructors are significant factors in student satisfaction and learning.

The COVID-19 pandemic precipitated the emergency pivot to remote instruction. Instructors did not have much time (if any) to prepare for this change, and likewise students had little time to prepare for the 
new remote-learning paradigm. Our results show that students missed the face-to-face interaction with their peers as well as their instructors. Generally, they seemed to dislike the remote learning environment. It must be emphasized that during that time, both students and faculty were dealing with issues both in and apart from the remote learning environment. They were dealing with anxiety, death, and the fear of the unknown, and these all could have had an impact on instruction and learning.

\section{DATA AND METHODOLOGY}

To investigate students' perceptions of emergency remote instruction during the COVID-19 pandemic, we designed a survey in which we asked students at a small, private university in the Midwest (United States) a series of questions. The survey instrument is in Appendix 1. The survey was programmed into Qualtrics, and then we sent a link to the survey via email to all undergraduate business students who were enrolled during the Spring 2020 semester. We distributed the survey after the end of the semester, and at the start of the study, we shared the data collection methods with the students and using consent and disclosure statements, assured them that their responses would remain anonymous. We received 258 respondents to our survey. After accounting for missing observations (skipped questions), our final sample included 247 observations, representing a response rate of about $21 \%$. Of the 247 respondents, $52 \%$ were female and $48 \%$ were male. The distribution by class year included first year (19\%), sophomore (29\%), junior (23\%), and senior (29\%) students, representing a good cross section of students at various stages in the business program. Likewise, this business school offers eight majors, and we received responses from students in every major, with the largest sample being from marketing majors (30\%) and finance majors $(25 \%)$.

Our fundamental objective was to understand students' perceptions of emergency remote instruction during the COVID-19 pandemic, as many institutions were forced to make the unexpected pivot from traditional to remote instruction. It is rare to have a sudden and unpredictable switch to online instruction, but the COVID-19 pandemic provided us with a precise natural experiment. Therefore, we asked students questions on the impact of this transition. We also wanted to understand whether these perceptions differed across various groups. Specifically, we tested differences in students' perception of emergency remote instruction during the pandemic based on gender, class, and self- identified introvert/extrovert personalities.

\section{RESULTS}

\section{Overall Results}

Our analysis began by asking students whether the emergency transition to online instruction affected their GPA. Most students are usually very concerned with their GPA, so we wanted to get a sense of whether they thought that their GPA had been affected by the disruption. We received the full range of responses to this question, with $35 \%$ of students saying that the transition had a positive effect on their GPA, $29 \%$ saying it had a negative effect, and $36 \%$ feeling there was no effect on their GPA. It should be noted that this university, like many others, gave Spring 2020 semester students the option to change grades to pass/fail, and this may have had an impact on the results.

We were interested in students' experiences with online instruction prior to the pandemic because this could have an impact (positive or negative) on their perception of the emergency pivot to remote instruction. More than half (55\%) of students said they had never taken an online course prior to this experience. Of those who had (45\%), nearly all had done so within the last 2 years. When asked to compare online to traditional instruction, a surprising $78 \%$ of students perceived online instruction to be inferior to traditional classroom teaching. Only 5\% of students perceived online instruction as superior, with the remaining students perceiving no difference in quality between the two methods of instruction.

In terms of the delivery of online courses during the pandemic, $20 \%$ were offered synchronously, $32 \%$ were offered asynchronously, and $48 \%$ were offered in a hybrid format. Nearly half (48\%) of the students preferred the hybrid format, and one third (33\%) preferred the asynchronous format. The remaining $19 \%$ preferred the synchronous (live on Zoom) format. Interestingly, $26 \%$ of students preferred core university 
(nonbusiness) courses in the online format. For the $84 \%$ who preferred business courses in the online format, the most favored course was economics (13\%).

To get a more in-depth understanding of students' learning styles, we asked the students how they learned best. The five most prevalent answers were learning via a hands-on approach, detailed instructions, detailed feedback, structure, and exchanging ideas with others. While each of these styles can be followed online, they all are more challenging than in the traditional classroom format, especially given the fact that faculty had virtually no time to prepare for the remote transition. This gives us further insight into the reasons students may have perceived remote instruction as being inferior. In addition, when asked, "Overall, to what extent did you like your Spring semester courses in an online format?", $50 \%$ of the students disliked or strongly disliked remote instruction during the COVID-19 pandemic. We understand that this may be due to the uncertainty of living in a pandemic, where any format of teaching would undoubtedly present challenges.

Next, we wanted to examine where professors had the biggest room for improvement to help students be more successful in an emergency remote environment. One key theme expressed by students was timeliness - both in posting class material (23\%) and in responding to email (16\%). Another theme was flexibility $(23 \%)$, which is a reasonable response given that the pivot to remote instruction occurred during a global pandemic. A professor's preparedness can also affect student learning; therefore, we asked students how many of their professors they thought were comfortable teaching in the emergency online format using new technology. Only $6 \%$ of students perceived all professors as being comfortable with the emergency online format and/or the use of technology. However, $71 \%$ of students felt that at least a few professors were comfortable with these changes. This is not surprising given that some professors did have previous online instruction experience, or were able to learn the technology quickly to transition to remote instruction. In fact, only about $15 \%$ of the business school faculty had previous online teaching experience. It is also worth pointing out that about $6 \%$ of students said that none of their professors seemed comfortable with the new remote format and/or the use of technology.

Research has shown that students should also be responsible for their success. Therefore, we asked students how they could improve in an online environment. In choosing among preset categories, students indicated "better time management," "minimizing distractions," and "staying focused" as the primary areas that need improvement. Interestingly, Internet service was not a problem for these students, with 92\% reporting that they have at least good Internet service at home.

The 2020 Spring semester brought new challenges to learning, as students and faculty found themselves in an emergency remote learning environment that they did not anticipate. Students cited family and social media distractions as additional impediments to learning in the remote environment. Additionally, 25\% of students reported worrying about the pandemic and/or future jobs (or internships), and this provided another layer of challenges to remote learning at the start of the pandemic. It is reasonable to assume that students with more anxiety about the pandemic and its impact on future work prospects will have a difficult time concentrating on their studies. Moreover, $87 \%$ of students reported missing the face-to-face contact with their professors, and $90 \%$ of students missed the face-to-face contact with their peers.

According to the Centers for Disease Control and Prevention (CDC), "fear and anxiety about a new disease and what could happen can be overwhelming and cause strong emotions in adults and children. Public health actions, such as social distancing, can make people feel isolated and lonely and can increase stress and anxiety." We asked students, "Overall, how was your personal well-being after the switch to online instruction?" Most students chose the responses of "good" (33\%), "average" (30\%), and "not very good" (24\%). The most concerning part of these responses is that taken with the response of "poor" $(5 \%)$, we see that about $28 \%$ of students reported below-average personal well-being after the emergency pivot to remote instruction. Only about $9 \%$ of students said that their personal well-being was excellent after this abrupt change as a result of the COVID-19 pandemic.

\section{Students' Perceptions of Online Instruction During COVID-19, by Subgroup}

We also wanted to determine whether students' perceptions of remote instruction during COVID-19 differed across gender, class, and personality trait (extrovert/introvert). In the following sections, we report 
results from an independent t-test on our sample to determine whether there were such differences in effect on GPA, liking the Spring 2020 online format, preferred class format (asynchronous, synchronous, hybrid), online cheating, missing professors and/or peers, and personal well-being after the emergency pivot to remote instruction.

\section{Gender}

There were no gender differences for students' perception of GPA being affected by the disruption as a result of the pandemic. Similarly, we did not find gender differences for liking the Spring semester online format, preference for class format, concern over online cheating, or missing face-to-face contact with professors and/or peers. On average, males and females reported 3.2 on a scale of 5 for "To what extent did you like your Spring courses in an online format?" where scores of 1 reflect "love it," 2 "like it," 3 "neither like nor dislike," 4 "dislike," and 5 "hate it." Thus, on average, students slightly disliked the Spring course remote format. As previously discussed, students preferred a hybrid format, and this did not vary across gender. Concern for cheating was on average 1.64 on a scale of not at all (0) to very much (4). Missing professors and/or peers was a dichotomous variable $(1=$ yes, $0=$ no $)$, and students on average missed peers (.90) more than professors (.87), but we found no differences when comparing results across gender.

Our most interesting results when comparing gender was the report of one's stated well-being. On average, females were more likely to report a poorer state of well-being after the pivot to remote instruction during the COVID-19 pandemic. The results show that female undergraduate students reported a significantly worse state of personal well- being ( 1.94 compared to 2.42 , where " 0 " is poor and "4" is excellent) during this time as compared to male undergraduate students $(\mathrm{p}<0.001)$.

\section{Class Year}

Next we tested for difference across class year (first year, sophomore, etc.). We first ran t-tests comparing means differences between students in their first or second year as compared to third and final year. No differences were observed for liking the Spring semester online format, preference for class format, concern over online cheating, missing face-to-face contact with professors, or personal well-being.

We found some support for differences by class year for how GPA was affected and missing peers. Students in later years of study (juniors or seniors) on average reported GPA as marginally adversely affected by the transition as compared to the other students (first year and sophomores). We report these findings cautiously because the difference in means is at $p<.10$. Similarly, a small difference $(p<.10)$ was found when comparing first-year students and sophomores to juniors and seniors. Students in their early years of study reported higher rates of missing their peers. These results may be explained in part by the fact that most students in upper classes (especially seniors) were living in apartments and quarantining with roommates (peers) during the start of the pandemic. On the other hand, most first- and second-year students were forced to return home to their parents.

To further examine whether seniors had a different experience, we ran the results again, comparing seniors to all other classes (first year, sophomore, and junior). We found one difference that strengthens and clarifies our earlier GPA results. Specifically, seniors on average reported that the remote transition had a more positive impact (1.62 on a scale of 2) on GPA, and this difference was statistically significant $(\mathrm{p}<.05)$. As discussed in the conclusion, this may be partly due to the university offering the option of pass/fail (in place of letter grades) for the Spring semester only. No other significant differences were found when comparing seniors to the other classes.

\section{Extroverted or Introverted Personality}

Of our student sample, $49 \%$ identify as introverts and $51 \%$ as extroverts. Our objective here was to test whether there were any differences between the personality traits on students' perception of online instruction during the pandemic. No differences were observed for GPA, liking the Spring semester online format, preference for class format, concern over online cheating, or personal well-being.

While we did not find any differences for missing the face-to-face contact with professors, we did find that extroverts on average reported missing the face-to-face interaction with their peers more than did 
introverts $(\mathrm{p}<0.01)$. These results are not too unexpected given that extroverts draw their energy from other people, but they are still noteworthy given that students specifically missed their peers during the pandemic.

\section{CONCLUSION}

This research explored students' perceptions of emergency remote instruction during the Spring (2020) semester and at the start of the COVID-19 pandemic. Higher education had a collective experience when the global pandemic created a world of social distancing and quarantining with little warning. Professors and administrators were forced to adjust to rules and regulations that now required distance from one another. Remote instruction became the only way to salvage the disrupted Spring 2020 semester. In this paper, our objective is to contribute to timely conversations about the impact of emergency remote instruction during the COVID-19 pandemic.

We examined students' perceptions of remote instruction during the COVID-19 pandemic from many different approaches such as grades, preferences for the online format, missing connections with professors and peers, and overall well-being. First, we found trends on overall student perceptions. For example, a large number of students said they missed their peers. Then we tested whether students' perceptions differed based on gender, class, and personality.

While some of our results did not show statistically significant differences across subgroups, we find this just as interesting as the results showing disparities. We interpret the results that showed few or no differences between groups as all students having a collective experience that transcends gender, class year, and personality type. For instance, we find that no matter their gender, class year, or personality, students on average did not like the Spring 2020 semester remote format and missed both their professors and their peers. Both of these results can be attributed to the abruptness of the change as well as the stressors that are inherent in living through a pandemic. In conversations with students outside of this survey context, we learned that there is a big difference (and mostly negative) between opting to enroll in a fully online class versus having a traditional class go online in the middle of the semester. Moreover, we also learned that given that the change happened so suddenly and without warning, there was little time, if any, for students to see and say goodbye to their peers.

The differences found across gender show us that females' well-being was negatively affected by the pandemic. This is extremely important as it shows that professors need to show empathy to students, especially during this difficult time. Likewise, we found that self-identified extroverts on average reported missing their peers, as they generally prefer to be with people and get their energy from being with others. Finally, seniors (and most students) felt that this unique experience had a positive effect on their GPA, which may be due to the fact that they had the option of switching grades to pass/fail during the Spring 2020 semester.

\section{PEDAGOGICAL IMPLICATIONS}

It is clear from our research that students have different perceptions and attitudes toward learning. In addition, students have different learning styles and different levels of motivation to learn. Given the findings in this study, it is imperative that instructors understand these differences and adjust their teaching styles in order to gain the highest level of student engagement, especially in a remote environment. Specifically, instructors need to do the following: (a) participate in ongoing professional development and technology training; (b) prepare carefully for their online classes; (c) be responsive to students via email, discussion boards, announcements, etc.; (d) be interactive in the online environment by using polling, breakout rooms, etc.; (e) stimulate further discussions on class topics; and (f) use various teaching styles such as lecture, large- group discussions, small-group discussions, and visual aids. 


\section{RESEARCH LIMITATIONS}

This study has a few limitations, which we offer as potential for future research. First, this survey was conducted among a group of students in a private university in the Midwest at the start of the pandemic. Therefore, other settings (for example, public universities) may yield different results. Second, because this study was responding to an immediate and unique set of circumstances, there have been no comparable published papers on students' perception of the emergency pivot to online instruction during the pandemic, and the authors created the survey questions based on related research. As such, there may be questions omitted from this study that should be included in future work. This offers an opportunity for future research to survey students in future semesters to see whether the results are highlighting the emergency remote situation as opposed to the online delivery of courses. Third, while the quantitative data gives us great insight into perceptions, developers of future studies may want to combine both quantitative and qualitative measures. For example, interviewing students to better understand the reasoning for responses or to gather more detailed experiences would add value to this timely topic. Finally, in the academic year following the Spring 2020 semester, universities found innovative ways to teach during a pandemic. One example is hyflex formats. Researchers may now want to explore the impact of other formats, and whether more planning and training during the summer months (2020) created a more positive experience for students in subsequent semesters.

\section{ENDNOTE}

1. https://www.cdc.gov/coronavirus/2019-ncov/daily-life-coping/managing-stress-anxiety.html

\section{REFERENCES}

Abrami, P.C., Bernard, R.M., Bures, E.M., Borokhovski, E., \& Tamim, R.M. (2011). Interaction in distance education and online learning: Using evidence and theory to improve practice. Journal of Computing in Higher Education, 23, 82-103.

Ascough, R.S. (2002). Designing for online distance education: Putting pedagogy before technology. Teaching Theology and Religion, 5(1), 17-29.

Bower, B.L. (2001). Distance education: Facing the faculty challenge. Online Journal of Distance Learning Administration, 4, 1-6.

Britt, R. (2006). Online education: A survey of faculty and students. Radiologic Technology, 77(3), 183190.

Cole, M.T., Shelley, D.J., \& Swartz, L.B. (2014). Online instruction, e-learning, and student satisfaction: A three year study. The International Review of Research in Open and Distributed Learning, 15(6). https://doi.org/10.19173/irrodl.v15i6.1748

Cutri, R.M., \& Mena, J. (2020). A critical reconceptualization of faculty readiness for online teaching. Distance Education, 41(3), 361-380.

Fein, A.D., \& Logan, M.C. (2003). Preparing instructors for online instruction. New Directions for Adult and Continuing Education, 100, 45-55.

Hinson, J.M., \& LaPrairie, K.N. (2005). Learning to teach online: Promoting success through professional development. Community College Journal of Research and Practice, 29, 483-493.

Joosten, T., \& Cusatis, R. (2020). Online learning readiness. American Journal of Distance Education, 34(3), 180-193.

Levy, S. (2003). Six factors to consider when planning online distance learning programs in higher education. Online Journal of Distance Learning Administration, 4(1). Retrieved from http://www.westga.edu/\%7Edistance/ojdla/spring61/levy61.htm

Li, Q., \& Akins, M. (2005). Sixteen myths about online teaching and learning in higher education: Don't believe everything you hear. Tech Trends: Linking Research and Practice to Improve Learning, 49(4), 51-60. 
Miller, M.D. (2021). Quotes: COVID-19 and extended online learning. Retrieved from https://www.sciline.org/covid-expert-quotes/online-learning

Mitchell, L.D., Parlamis, J.D., \& Claiborne, S.A. (2015). Overcoming faculty avoidance of online education: From resistance to support to active participation. Journal of Management Education, $39(3), 350-371$.

Muirhead, W.D. (2000). Online education in schools. International Journal of Educational Management, 14(7), 315-324.

Palvia, S., Aeron, P., Gupta, P., Mahapatra, D., Parida, R., Rosner, R., \& Sindhi, S. (2018). Online education: Worldwide status, challenges, trends, and implications. Journal of Global Information Technology Management, 21(4), 233-241.

Parlamis, J., \& Mitchell, L.D. (2014). Teaching negotiations in the new millennium: Evidence-based recommendations for online course delivery. Negotiation Journal, 30, 93-113.

Phipps, R., \& Merisotis, J. (2000). Quality on the line: Benchmarks for success in Internet-based distance education. The Institute for Higher Education Policy. Retrieved from http://www.ihep.com/Pubs/PDF/Quality.pdf

Protopsaltis, S., \& Baum, S. (2019). Does online education live up to its promise? A look at the evidence and implications for federal policy. Retrieved from https://jesperbalslev.dk/wpcontent/uploads/2020/09/OnlineEd.pdf

Richardson, J.C., Maeda, Y., Lv, J., \& Caskurlu, S. (2017). Social presence in relation to students' satisfaction and learning in the online environment: A meta-analysis. Computers in Human Behavior, 71, 402-417.

Shearer, R.L., Aldemir, T., Hitchcock, J., Resig, J., Driver, J., \& Kohler, M. (2020). What students want: A vision of a future online learning experience grounded in distance education theory. American Journal of Distance Education, 34(1), 36-52.

Sher, A. (2009). Assessing the relationship of student-instructor and student-student interaction to student learning and satisfaction in web-based online learning environment. Journal of Interactive Online Learning, 8(2), 102-120.

Singh, V., \& Thurman, A. (2019). How many ways can we define online learning? A systematic literature review of definitions of online learning (1988-2018). American Journal of Distance Education, 33(4), 289-306.

Wei, H-C., \& Chou, C. (2020). Online learning performance and satisfaction: Do perceptions and readiness matter? Distance Education, 41(1), 48-69.

Wickersham, L.E., \& McElhany, J.A. (2010). Bridging the divide: Reconciling administrator and faculty concerns regarding online education. Quarterly Review of Distance Education, 11(1), 1-12. 